\title{
GOULART, Mônica Helena Harrich Silva. A Dança das Cadeiras: Análise do Jogo Político na Assembleia Legislativa do Paraná (1889- 1930). 2014, 422 p.
}

\author{
Glória Estevinho ${ }^{1}$
}

- Enviado em 29/05/2015

- Aprovado em 29/08/2015

A Dança das Cadeiras, fala sobre o funcionamento da Assembleia Legislativa do Paraná (ALEP). Adotando o conceito bourdisiano de sub-campo, analisa a concentração do jogo político e das relações de poder no Estado do Paraná entre 1889-1930. É de Bourdieu, ainda, a orientação para a compreensão do sentido do conceito de campo, habitus, jogo e interesse, onde é delineado o agir politicamente através da ocupação de um cargo em um órgão estratégico de manutenção do poder. Todo o contexto geográfico, histórico, econômico e sociológico da Primeira República é minuciosamente investigado pela autora, com vistas a desvendar o poder Legislativo e seus mecanismos políticos, que ao longo da República Velha, determinaram a distribuição de poder no Estado. O Legislativo é o alvo de estudo, por configurar-se num reduto de passagem para o Executivo e romper o paradigma de submissão, ou seja, invertidas as dependências observou-se o quanto a ALEP configurou-se num lócus de concentração de ‘apadrinhamentos' e efetivação do coronelismo, bem como da política dos governadores.

A partir da definição de classe dominante, desenvolvido por Marx, a autora identifica a composição dos cargos políticos dentro da ALEP, sendo esses o centro do poder do Paraná, onde público e privado se misturam se confundem e se traduzem em capital político. Política dos Governadores e coronelismo são dois recursos metodológicos e históricos resgatados para explicar o jogo político desse subcampo. O Coronelismo é um fenômeno político, econômico e social, que revela a situação de dependência do Coronel para realização das benesses distribuídas

\footnotetext{
${ }^{1}$ Graduada em Ciências Sociais pela Universidade Federal do Paraná. Pós Graduada em Sociologia Política pela Universidade Federal do Paraná. Atualmente atua como docente compondo o Quadro Próprio do Magistério no Governo do Estado do Paraná. Endereço eletrônico: geg@seed.pr.gov.br
} 
entre seus apadrinhados e dependentes da fazenda ${ }^{2}$, uma via de mão dupla permitia o desenvolvimento de um sentimento de fidelidade capaz de garantir a indicação de candidatos a cargos públicos. A fraqueza do coronel é um paradoxo garantidor da obtenção de benefícios junto ao Município e a outras instâncias do poder público. O Coronel é quem angaria votos e garante eleições. O coronel é quem concede favores. A relação de troca é evidente e necessária, diante da miséria humana, intelectual que assolava o período em questão. A garantia da permanência de um "curral eleitoral” é tarefa também dos coronéis. Todas as questões ligadas ao coronelismo são fatores para a construção de um capital político que abrem as portas da ALEP, então sua manutenção se dá pela permanência deste capital, isso perpetua o jogo, mantém o político, enfim garante o cargo. As fraudes eleitorais, comum na Política dos Governadores, não são mais o essencial, porém, não estão totalmente descartadas, o que acontece é que quando se entra na lógica deste subcampo, torna-se menos importante, uma vez que o jogo se sobrepõe. Ter indicação para ocupar uma cadeira dentro da ALEP é garantia de pertencimento ao jogo, bem como indicativo de capital político suficiente para circular, ou indicar nomes ao Executivo.

Com Karl Mannheim a discussão assume outra conotação, o da investigação das transições, via gerações no poder. Como um grupo e outro se sucedem e quais os mecanismos acionados para que isso se efetive? Há a constatação de que os parlamentares estabelecem relações políticas com o executivo durante a Primeira República de modo a somar em seus capitais políticos efetivando lideranças dentro da ALEP, bem como, por esse ato, tornam-se conhecidos dentro do Estado do Paraná. Assim, a transição geracional vai se formando pelas influências dos grupos e também por influenciar. Neste contexto, as sucessões ocorrem a partir da verificação de suas trajetórias de uma geração a outra, pois constata-se a existência de dois grupos que se alternam no poder em busca do Executivo Estadual. Essa análise de gerações implica em fatores biológicos a serem levantados, toda questão de socialização política é levada em consideração, e correlacionada a processos históricos, sociais e culturais de modo a identificar os atores a uma época. A questão posta aqui é o da identidade geracional, que não

\footnotetext{
${ }^{2}$ Toda conjuntura culmina nesse quadro, cujo debate é feito com Vitor Nunes Leal, em seu livro Coronelismo, enxada e voto.
} 
acontece pelo simples fato de viver na mesma época, é preciso experiência tal que o identifique, enquanto pertencente a mesma geração. ${ }^{3}$

Todos querem sua fatia do bolo, assim há gerações que disputam o poder e, de um lado, são representantes da 'velha guarda', que somam a seus nomes e representações políticas - uma geração de capitais culturais - simbolizando toda carga de conhecimentos adquiridos durante a passagem pelo Império, e não querem perder o poder, mas que, de certo modo, sentem que as regras estão mudando e lutam pela sua cadeira. De outro lado, quase que naturalmente, outra geração vai se formando e, agora são os 'filhos da República' que almejam entrar nesta dança. A análise das gerações mostra que os campos serão ocupados pelo jogo estabelecido então fica implícito o choque de gerações, certo? Errado porque, na verdade, tudo acontece dentro da maior 'lisura' e sem evidências de conflito, afinal o jogo é facilmente adaptado pela habilidade de nossos políticos paranaenses. A capacidade de adaptação, também as fusões, são as características apresentadas nesta obra. Essas características amenizam, em certa medida, o conflito, conciliam as gerações e, também, geram novas demandas. No diálogo com Ricardo Costa Oliveira ${ }^{4}$, degustando os frutos de pesquisa desenvolvida no estudo das famílias que compõem o poder no Paraná, a expressão nepotismo, explica essa continuidade e brandura nos conflitos - deixa sua marca: a dos sobrenomes e vínculos familiares, e garante a continuidade nos quadros da política, é o caso, citado pela autora, de Bento Munhoz da Rocha, Alves de Camargo e Rocha Loures que vem de outrora compondo cargos estratégicos da classe dominante no Estado.

A análise geracional proposta, investiga duas gerações de Governos eleitos: Generoso Marques, Francisco Xavier da Silva, José Pereira dos Santos Andrade, Vicente Machado, João Candido Ferreira e Carlos Cavalcanti, que fazem parte da primeira geração constituída ao longo

\footnotetext{
${ }^{3}$ Para tanto, foi preciso construir na análise uma unidade geracional para avançar o estudo sobre o Executivo, nas palavras da autora: "É a partir do conceito de unidade de geração que será pensado o Executivo paranaense de forma mais específica, uma vez que àquele grupo de homens que compartilham politicamente o mesmo período é extremamente amplo, correspondendo desde a massa de eleitores que fazia parte do mesmo processo político ao qual se estruturava a política do Estado e até mesmo dos próprios coronéis que comandavam politicamente seus respectivos municípios, mas, entretanto, não compartilhavam o poder de fato do Executivo do estado. Daí a importância de se analisar os Governadores do estado enquanto unidade de geração, porque tal conceito expressa melhor a realidade concreta da época, até porque, conforme já destacado, diante de vários Governos Provisórios e passageiros, foram poucos os atores políticos que detiveram o Governo do estado em suas mãos. ” (pag.89)
}

${ }^{4}$ Para um aprofundamento desse tema, consultar OLIVEIRA, Ricardo. Na Teia do Nepotismo. Curitiba: Insight, 2012. Além dos já citados OLIVEIRA, Ricardo. Famílias, poder e riqueza: redes políticas no Paraná IN: Sociologias, Porto Alegre, 2007; OLIVEIRA, Ricardo. O silêncio dos vencedores: genealogia, classe dominante e Estado no Paraná. Curitiba: Moinho do Verbo, 2001 
da Primeira República. Cabendo a Affonso Camargo e Munhoz da Rocha encabeçar a segunda geração e, compor o novo quadro político do Paraná até 1930. Na análise da primeira geração, pode-se dizer que carregou em seu habitus os resquícios do Império promovendo as adaptações no campo, conforme as demandas de seu contexto, tanto quanto a segunda geração que o faz, a partir da conciliação de suas perspectivas ideológicas vinculadas a nova conjuntura.

Durante a Primeira República a ALEP foi lócus de articulações e estruturações político partidárias, segundo a autora, então, nesta parte da obra, é o que nos mostra, bem como os elementos que garantiam os arranjos e sustentação do jogo dentro deste subcampo. As características do coronelismo, no Paraná, possibilitaram um quadro de influências e relações com o Executivo que fazem deste subcampo um meio de aquisição e agregação de capital político que, conforme a situação, oscila o grau de importância e concessão, mas é o que permite almejar novos cargos. A transição do regime foi marcado pelo embate político e, para a consolidação partidária, as cartas na manga da coerção e da fraude eram os meios políticos válidos, bem ao estilo coronelista e que, por suas características, tornaram-se fonte de pesquisa e permitem a descrição do referido órgão. Ainda neste quesito, vale acompanhar as discussões da economia da época cujos interesses madeireiros e ervateiros de um projeto de desenvolvimento conservador se fazem presente. Esses interesses davam os subsídios para a manutenção de uma classe dominante que já era 'cria' do Império. A questão político partidária revela a existência de um bipartidarismo cuja nomenclatura varia conforme a época e que gira em torno de, basicamente, duas legendas PRF (Partido Republicano Federal) e UR (União Republicana) e que após 1908 se fundem para criar o PRP (Partido Republicano Paranaense). Essa fusão é fruto de discussões e rivalidades, cujo resultado político fica evidente enquanto processo de transição para agregação de capital político. Nota-se, então, que isso faz parte dos ajustes da transição. As legendas são parte do processo, vale ter em mente que, essas articulações são artifícios usados para a manutenção da classe dominante, uma vez que os rivais de outrora se tornam amigos em nome de um capital político significativo para obtenção do poder. O surgimento de algumas legendas e manobras, ocorridas em seu interior servem para identificar as posições e oposições, a construção do capital político, suas mudanças com o propósito de ocupação de cargo dentro da ALEP, cuja possibilidade de chegar ao Executivo era mais próxima, de modo que, os partidos figuravam como arranjos necessários para projetar-se enquanto possibilidade de disputa. Pertencer ao partido situacionista era ser competitivo, era acumular capital político, era 
desenvolver o habitus próprio do jogo e almejar uma cadeira e poder, enfim, realizar a dança das cadeiras.

As alterações que a constituição de 1892 dispõe em relação ao voto de censitário a maior de 21 anos e alfabetizado o que amplia o eleitorado e favorece as práticas coronelistas de fraudes e o curral eleitoral, isso porque a proposta oposicionista não atingiu a força necessária para derrubar o poder estabelecido do partido da situação. O quadro apresentado é o do desmonte oposicionista de tal modo que o bipartidarismo seja uma falácia capaz de fazer prevalecer o situacionismo que fora questionado por Afonso Camargo, quando este era oposição de Vicente Machado, mas que por conta de seu falecimento ocupa a liderança do Partido Republicano Federal - reformulado em 1908 - mas com o mesmo habitus reproduzidos em seu interior de um situacionismo viciado nos ranços do Império.

Na sequência de fatos pesquisados estão as considerações sobre os papéis do Executivo e do Legislativo, onde a autora revela a submissão da ALEP. Esse subcampo é palco do jogo político que figura no Estado. Os fatos encontrados demonstram o grau de importância destinado à votação de cada tema, sendo que os favores e os interesses individuais se chocam com, o que deveria ser o verdadeiro papel da casa do povo. Os interesses pessoais são valorizados em detrimento ao poder público. Transformando a máquina, nas palavras de Marx, "em um escritório a serviço da classe dominante”.

Política e conflito estão intimamente ligados pela marca da disputa de interesses individuais ou de grupos. A investigação sobre a ALEP, realizada pela autora, além de demonstrar as habilidades em promover uma verdadeira dança das cadeiras, ao analisar os 40 anos de poder público camuflado pela regência do poder privado nos remete a construção de um modelo historicamente construído e elitizado, cujos privilégios são legitimados pelo sistema. Essa relação é perceptível pela condição econômica (ervateiros e madeireiros), num primeiro momento, o de adesão a um seleto grupo legislador, e dentro do modelo do sistema coronelista; num segundo momento por suas reconfigurações objetivando rearticular-se para permanecer no situacionismo, que já era a marca da casa antes da reforma de 1908. Esse fato mostra que em termos de mudanças tudo corroborou para permanecerem na mesma estrutura de poder, as reconfigurações foram o emblema da troca de mandatário e não de modelo de gestão. 